\title{
Effect of Artocarpus Heterophyllus Latex on Properties of Calcium Carbonate Filled Natural Rubber/Low Density Polyethylene/ Waste Polyethylene Composites
}

\section{Sampath WDM*, Sandaruwan PD, Edirisinghe DG and Sudusingha YCY}

Rubber Research Institute of Sri Lanka, Sri Lanka

*Corresponding author: Manjula Sampath, Rubber Research Institute of Sri Lanka, Telawala Road, Ratmalana, Sri Lanka, Tel: +94772548221; Email: wikcramage@yahoo.com

\section{Research Article \\ Volume 4 Issue 1}

Received Date: February 07, 2020

Published Date: March 09, 2020

\section{Abstract}

Artocarpus Heterophyllus Latex (AHL) is an aqueous emulsion containing many ingredients, for instance, lipids, rubbers, resins, sugars, proteins including proteolytic enzymes. Waste PE (wPE) is one of the major threats to the environment and, hence recycling of wPE is a way to reduce environmental pollution. The main aim of this study was to develop natural rubber (NR) / low density polyethylene (LDPE) /wPE composites with improved properties using AHL as a coupling agent. A series of 30:60:10 NR: LDPE: wPE composites was prepared by varying AHL loading from 0 pphp (part per hundred parts of polymer) loading to $2.5 \mathrm{pphp}$ at $0.5 \mathrm{pphp}$ intervals. $20 \mathrm{pphp}$ of calcium carbonate was also incorporated into every blend composition. The composites were prepared using a laboratory scale internal mixer by melt mixing at a temperature of $150^{\circ} \mathrm{C}$ and a rotor speed of $60 \mathrm{rpm}$. Physico-mechanical property and Fourier Transform Infrared (FTIR) analyses of the composites were conducted. Water absorption capacity, percentage swelling and gel content of the composites were also studied. The composite with AHL loading 1.5 pphp showed remarkable improvement in physico-mechanical and chemical properties than the other counterpart in terms of tensile strength, elongation at break, hardness, percentage swelling and gel content. It was observed that water absorption of composite has increased with the increase of the AHL loading. Results in overall indicated that the 1.5 pphp loading AHL composite is the best in terms of properties addressed in this study.

Keywords: Artocarpus heterophyllus latex; Low density polyethylene; Natural rubber; Polymer composites; Waste polyethylene

\section{Introduction}

Artocarpus heterophyllus (jackfruit) belongs to the family Moraceae, which is widely distributed in tropical areas including Sri Lanka. Jackfruit is also a rubber-producing plant, as all parts of the tree contain sticky white latex $[1,2]$. Jackfruit latex is an aqueous emulsion found in the vacuoles of special secretory cells known as laticifers, which contain lipids, rubbers, resins, sugars, enzymes and many proteins [3]. Jackfruit latex is used as a gum or resin for difference adhesive based applications. Furthermore, jackfruit latex yields $71.8 \%$ resin, consisting of $63.3 \%$ fluavilles (yellow) and $8.5 \%$ albanes (white) [4]. These resins may be valuable in varnishes.

wPE is a used or discarded material, which is not reused for the same application and properties would be lower as it has been already used. However, wPE could be used as a raw material for production of thermoplastic elastomer blends, which are considered as a unique class of materials playing a major role in the polymer industry nowadays $[5,6]$. LDPE is a thermoplastic, which is produced by free radical polymerization of ethylene monomer and defined by a density range of $0.910-0.940 \mathrm{~g} / \mathrm{cm}^{3}$. It has high degree 
of long chain branching. The high degree of branches with long chains gives molten LDPE unique and desirable flow properties. LDPE enables the polymer as a packaging and roofing material and for agricultural, electrical cable and other applications. Also, in this study, LDPE and wPE were used as the thermoplastic or plastic phase.

NR is cheaper and, it has high resilience (elasticity) and strong tensile and tear properties, which makes it more suitable material for shock and vibration isolators. Massive quantities of natural rubber are used in rubber manufacturing to produce quality rubber end products. Compounding rubber with additives is the best procedure that fulfills the given application with respect to properties, cost, and process involved. However, the blending of wPE with polymer and filler materials is more difficult, and many transitional situations can occur. Therefore, bonding agents or coupling agents are needed to reduce some of such difficulties and to achieve better performance of the final composite. As it contains large amounts of resins, therefore, in this study AHL was used as a coupling agent to enhance physical, mechanical and chemical properties of composites of NR, LDPE and wPE through $\mathrm{CaCO}_{3}$.

\section{Methodology}

\section{Materials}

Natural rubber (RSS-2) was supplied by the Dartonfeild Rubber Factory owned by Rubber Research Institute of Sri Lanka. LDPE was supplied by Deluxe Plastics Ltd., Sri Lanka. Calcium carbonate $\left(\mathrm{CaCO}_{3}\right)$ filler having a mean particle size of $2 \mu$ was obtained from Lanka Minerals \& Chemicals (Pvt.) Ltd., Sri Lanka. Sulphur (vulcanizing agent), stearic acid and zinc oxide (ZnO) (activator system), N-tert-butyl2-benzothiazole sulfenamide (TBBS) (accelerator) and IPPD (N-isopropyl N'-phenyl p-phenylene diamine) (antioxidant) were purchased from the local market. Artocarpus Heterophyllus Latex (AHL) was collected from Kurunegala, Sri Lanka [7].

\section{Preparation of NR/LDPE/wPE Composite Compounds}

A series of NR/LDPE/wPE composites was formulated by varying AHL loading from 0 to $2.5 \mathrm{phpp}$. Firstly, AHL was dried at room temperature and then converted into powder form. The formulation of the composites is given in Table 1 . The composite without AHL was considered as the Control. The composites were prepared by melt mixing using a Brabender Plasticorder operated at a temperature of $130^{\circ} \mathrm{C}$, and at a rotor speed of $60 \mathrm{rpm}$. Total mixing time was kept constant at 14 minutes. Mixing cycle used in the preparation of the composite compounds is given in Table 2.

\begin{tabular}{|c|c|}
\hline Ingredient & $\begin{array}{c}\text { Parts per Hundred Parts of Polymer } \\
\text { (pphp) }\end{array}$ \\
\hline NR & 30 \\
\hline LDPE & 60 \\
\hline wPE & 10 \\
\hline CaCO3 & 20 \\
\hline Sulphur & 0.5 \\
\hline Zinc oxide & 1.5 \\
\hline Stearic acid & 0.6 \\
\hline TBBS & 0.5 \\
\hline IPPD & 0.6 \\
\hline AHL & $0,1,1.5,2.0,2.5$ \\
\hline
\end{tabular}

Table 1: Formulations of the NR/LDPE/wPE composites.

\begin{tabular}{|c|c|}
\hline Total Time (min) & Ingredient \\
\hline 0 & LDPE+wPE \\
\hline 4 & NR \\
\hline 6 & ZnO + Stearic acid +IPPD \\
\hline 7 & $1 / 2$ CaCO3+ $1 / 2 \mathrm{AHL}$ \\
\hline 9 & $1 / 2$ CaCO3+1/2 AHL \\
\hline 11 & TBBS \\
\hline 12 & Sulphur \\
\hline 14 & Dumping the compound \\
\hline
\end{tabular}

Table 2: Mixing cycle.

NR/LDPE/wPE composites were compressed in an electrically heated hydraulic press at $150^{\circ} \mathrm{C}$ under 3.5 bar pressure for 15 minutes to produce $2 \mathrm{~mm}$ thick sheets. The processing conditions and compression moulding conditions were selected within the standard parameter ranges used in preparation of NR/LDPE/wPE composites. Test specimens were stamped from the moulded sheets according to the standards.

\section{Determination of Physico-Mechanical Properties}

Tensile properties and tear strength of NR/LDPE composites were determined according to BS ISO 37:2010 and BS ISO 34-1:2010, respectively using an Instron tensile testing machine. Dumb-bell tensile test specimens and angle tear test specimens were used. Hardness of the composites was determined using a Wallace Shore A hardness tester according to BS ISO 48:2010.

\section{Analysis of Degree of Swelling}

Three test pieces with dimensions of $30 \mathrm{~mm} \times 1 \mathrm{~mm} \times 2$ $\mathrm{mm}$ from each of the composites were tested. The test pieces were immersed in toluene for 72 hours in closed bottles. The percentage swelling value $(Q)$ was calculated according to 
the equation given below.

$$
Q=\left(\frac{m-m_{0}}{m_{0}}\right) X 100
$$

Where, $\mathrm{m}_{0}$ and $\mathrm{m}$ are masses of the test pieces before and after swelling.

\section{Analysis of Gel Content}

Three test pieces (approximately $1 \mathrm{~cm} \times 3 \mathrm{~cm} \times 0.2 \mathrm{~cm}$ in size) from each composite were tested. The test pieces were measured to the nearest $0.1 \mathrm{mg}$ and covered with a mesh and placed in boiled p-xylene for 16 hours. The test pieces were oven dried at $70^{\circ} \mathrm{C}$ and the weight was measured every hour until the readings became constant. The percentage gel content $\left(\mathrm{Q}^{1}\right)$ was calculated according to the equation given below.

$$
Q^{1}=\frac{m}{M} X 100
$$

Where, $\mathrm{M}$ is the initial mass and $\mathrm{m}$ is the mass after oven drying.

Further, hardness of the gel was measured using a Wallace Shore A hardness tester.

\section{Analysis of Percentage of Water Absorption}

Percentage water absorption of the composites was assessed by immersion in water at room temperature for 72 hours. Upon removal, specimens were dried and weighed immediately. The readings were taken in each hour until the weight was constant. The increase in weight is reported as percentage gained.

\section{FTIR Spectroscopy}

FTIR spectra of the oven dried gels were obtained using attenuated total reflectance (ATR) technique, using a Nicolet 380 FTIR spectrometer [8]. Spectra were recorded in the range of 400 to $3500 \mathrm{~cm}^{-1}$ operated at a resolution of $4 \mathrm{~cm}^{-1}$.

\section{Results and Discussion}

\section{Physico-Mechanical Properties of NR/LDPE/ wPE Composites}

Figure 1 shows stress-strain curves of NR/LDPE/wPE composites. Stress-strain curves are an especially necessary graphical measure of a polymeric material's mechanical properties like tensile strength, modulus, and elongation at break and facilitate in conniving Young's modulus and explaining material behavior. According to Figure 1, each graph shows a similar pattern and semi-crystalline behavior. The composite prepared with 1.5 pphp loading of
AHL showed better stress and strain behavior than other composites.

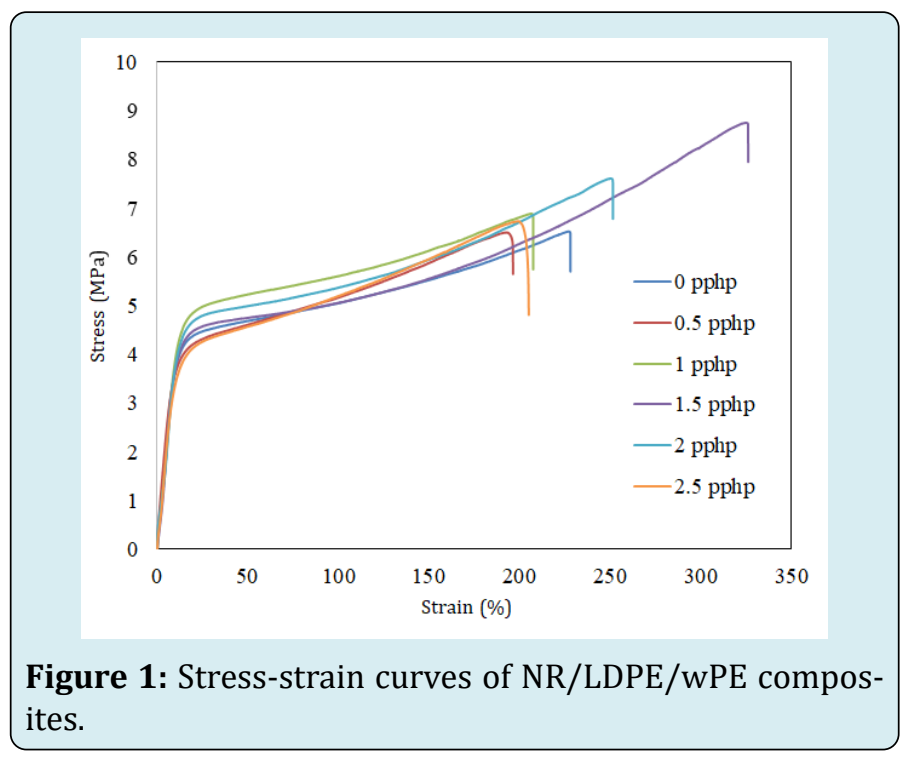

Figure 2 indicates the tensile strength of NR/LDPE / wPE composites with increasing AHL loading. It shows a marked increase of tensile strength from AHL loading of $0.5 \mathrm{pphp}$ to $1.5 \mathrm{pphp}$. The tensile strength of the composite of 1.5 pphp loading of AHL is higher than that of the other composites. The reason behind the higher tensile strength of the former composite could be attributed to good inter molecular interaction between the two polymer phases and lower surface tension at the interface [9]. This in turn would result in making a good intermediate between NR and LDPE. However, tensile strength has gradually decreased from 1.5 pphp to $2.5 \mathrm{pphp}$ loading as AHL may react as a plasticizer at high loadings.

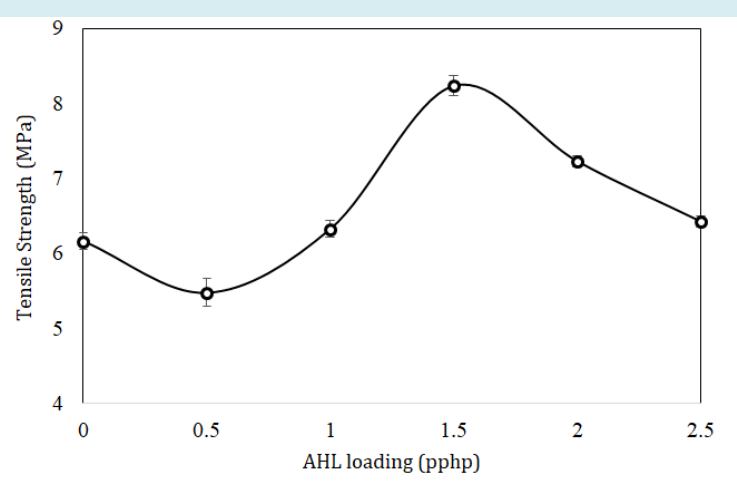

Figure 2: Tensile strength of NR/LDPE/wPE composites.

Elongation designates elasticity and amorphous behaviour of a polymer material. Figure III shows a sine pattern of elongation at break from AHL loading of $0 \mathrm{pphp}$ to $2.5 \mathrm{pphp}$. There is a significant variation from AHL loading of 0 pphp to 2.5 pphp. The composite with AHL loading of 1.5 
pphp shows the highest elastic properties compared to the other composites. This could be due to good dispersion of the filler $\mathrm{CaCO}_{3}$ through AHL. AHL contains $\mathrm{CH}_{3}$ and $\mathrm{OH}$ groups which are essential to make chemical interactions among the polymer material and hydrophilic filler material (Bhadra et al., 2019). Hence, AHL has made linkages between polymer material and filler. The composite with AHL loading of 0.5 pphp exhibits the lowest elongation at break. Further, higher loadings of AHL would affect to increase the flexibility of NR/ LDPE/wPE composite (Figure III) due to AHL containing $72 \%$ of resin (Orwa et al., 2009). Furthermore, this resin has a good adhesive effect to make strong chemical links among the polymer to polymer and polymer to filler.

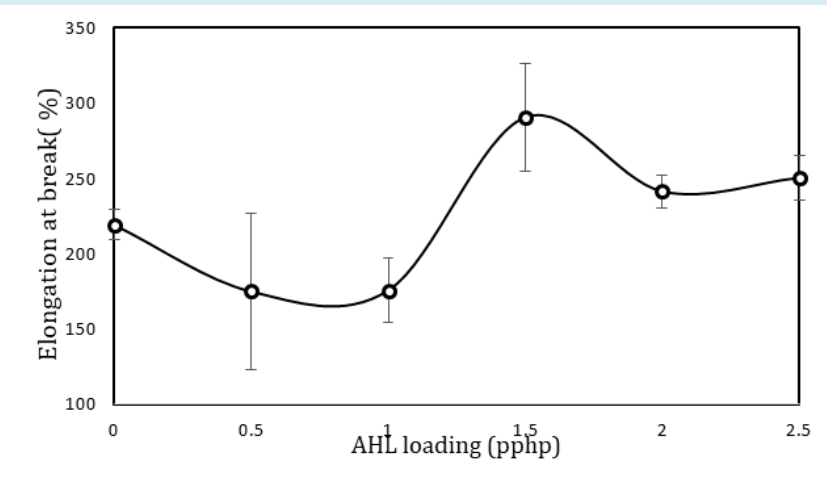

Figure 3: Elongation at break of NR/LDPE/wPE composites.

Hardness of NR/LDPE/wPE composites at different AHL loadings is shown in Figure IV. Hardness of all composites was in the range of 96 to 98 IRHD. According to Figure 4, composites prepared with AHL loading of 1.5 pphp showed the highest hardness value and it reflected high crosslink density at AHL loading of 1.5 pphp. Further, hardness has decreased from $1.5 \mathrm{pphp}$ to $2.5 \mathrm{pphp}$ AHL loading. This is due to the fact that high loading of AHL would act as a plasticizer and it decreases the viscosity of the NR/LDPE/ wPE composites.

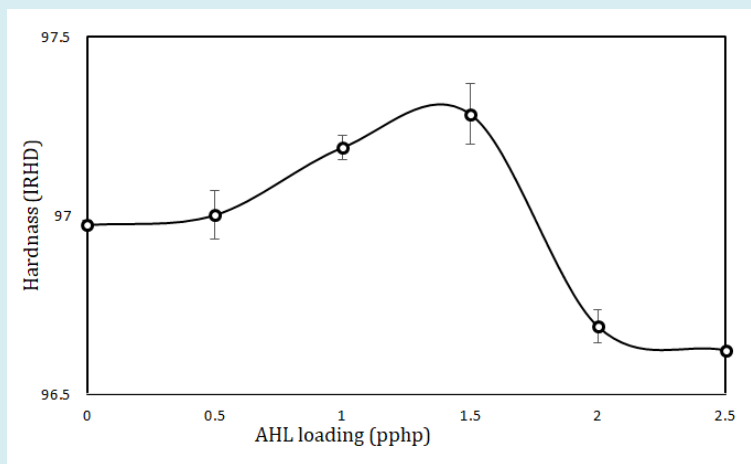

Figure 4: Hardness of NR/LDPE/wPE composites.
Figure 5 indicates tear strength of NR/LDPE/wPE composites at different AHL loadings. Composite prepared with AHL loading of 0.5 pphp showed the highest tear strength in comparison to other counterparts. Also, composites prepared with AHL loadings from $1.5 \mathrm{pphp}$ to 2.5 pphp do not show significant variation in tear strength and this conforms that more than $1.5 \mathrm{pphp}$ AHL loading would not effect to enhance the tear performance of NR/LDPE/wPE composites. Tear strength indicates the crack propagation property of a polymeric material. If the tear strength is high, it indicates that the material has good adhesion between the NR, LDPE and wPE phases and fine phase morphology. Sampath et al., (2019) reported that in NR/LDPE blends prepared with a titanate coupling agent, tear strength decreased at high titanate coupling agent loadings. Coupling agent acts as a plasticizer at high loading and decreases the crystallinity of polymeric material. Therefore, a variation in tear strength similar to that of titanate is observed when AHL is being increased. .

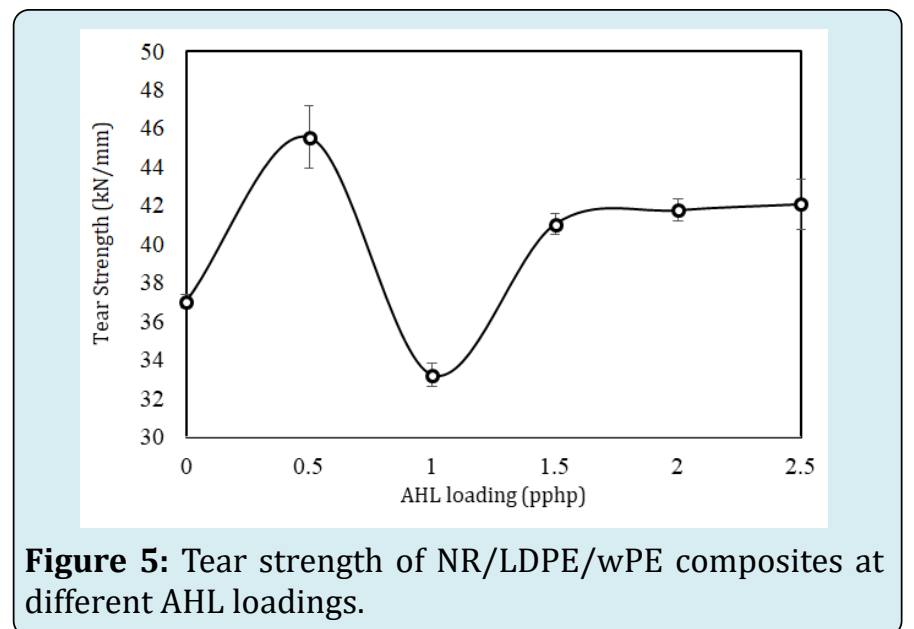

\section{Water Absorption of NR/LDPE/wPE Composite}

As per Figure 6, water absorption of all the composites is less than $0.35 \%$ and this is due to the organic nature of NR and LDPE polymers, and hence they do not react with inorganic water molecules. The composite prepared with AHL loading of $2 \mathrm{pphp}$ indicated the highest water absorption and it could be due to the presence of high amount of polar substances like phenolic and alcoholic substances [12]. The lowest water absorption at AHL loading of $0.5 \mathrm{pphp}$ confirms a good adhesion between NR and LDPE phases of the composites at this AHL loading. However, composites with AHL loadings show higher water absorption and it may be due to the presence of excess AHL, which makes a weak interface between $\mathrm{CaCO}_{3}$ and polymer [13]. High porosity created at higher AHL loadings absorbs higher degree of water. Good interfacial adhesions and good $\mathrm{CaCO}_{3}$ dispersion developed in the composite of $0.5 \mathrm{pphp}$ AHL loading inhibited creation of porosity and hence showed the lowest water absorption. 


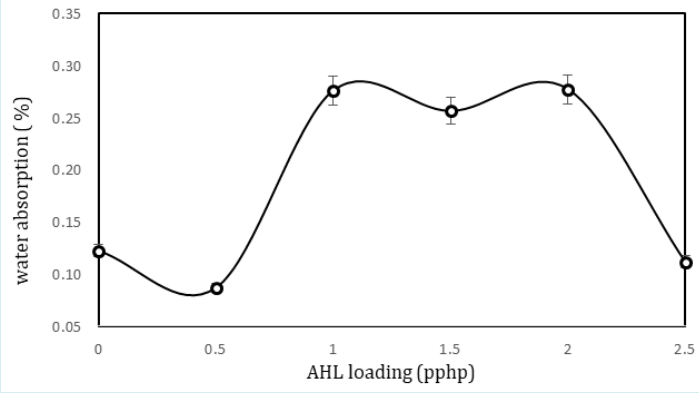

Figure 6: Water absorption of NR/LDPE/wPE composites.

\section{Fourier Transform Infrared (FTIR) Spectroscopic}

\section{Analysis}

Figure 7 presents the FTIR spectra of the composites at different AHL loadings. The composite prepared with AHL loading of $2.5 \mathrm{pphp}$ exhibits a peak assignment at $1264 \mathrm{~cm}^{-1}$ (Figure 7c). This could be assigned to $\mathrm{C}(0)-0$ stretching vibrations and $-\mathrm{OH}$ in-plane vibrations or amide [14]. Therefore, these $\mathrm{OH}$ and $\mathrm{C}(\mathrm{O})-\mathrm{O}$ groups are supported to react with $\mathrm{CaCO}_{3}$ and make compatibility between polymer (NR, LDPE) and filler $\left(\mathrm{CaCO}_{3}\right)$. In all composites present symmetric $\mathrm{CH}_{3}$ group at $2917 \mathrm{~cm}^{-1}$ is present.

Thus, the formation of above bonds proves that the composite with AHL loading of $1.5 \mathrm{pphp}$ achieved an interaction between NR, LDPE, and other ingredients. Further, the composite prepared with AHL loading of 1.5 pphp indicates a peak assignment at $1441 \mathrm{~cm}^{-1}$ (Figure 7c). This could be assigned to $\mathrm{C}=0$ stretching vibration [15]. Hence, $\mathrm{C}=0$ would be supported to make proper interaction with $\mathrm{CaCO}_{3}$ and AHL. Therefore, 1.5 pphp loading composite shows better properties than the other counterparts. In addition, $\mathrm{CaCO}_{3}$ reacts with $\mathrm{OH}$ group and make the bonds at the surface of $\mathrm{CaCO}_{3}$ and NR, LDPE and wPE make interactions with $\mathrm{CH}_{3}$ group. Therefore, AHL reacts as a chemical bridge between inorganic filler and the polymer material.

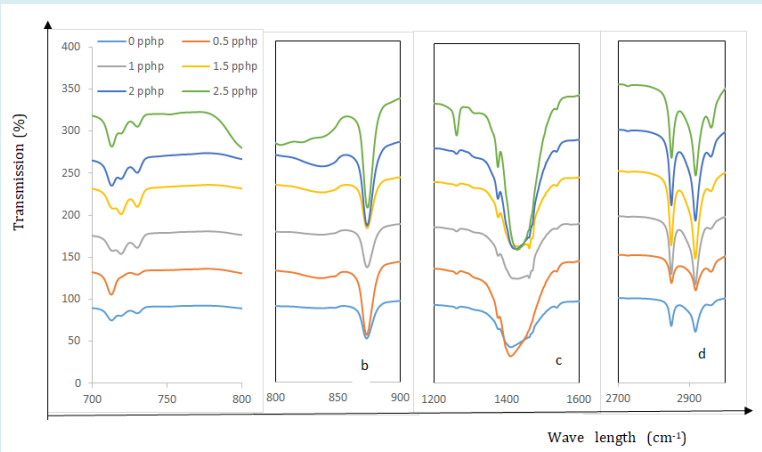

Figure 7: FTIR spectra of gels of the composites with AHL for different regions a) 700 to $800 \mathrm{~cm}^{-1}$ b) 800 to $900 \mathrm{~cm}^{-1}$ c) $1200-1600 \mathrm{~cm}^{-1}$ d) $2700-3000 \mathrm{~cm}^{-1}$.

\section{Swelling and Gel Content of NR/LDPE/wPE Composite}

Swelling property of a thermoplastic elastomer defines the chemical or liquid absorption capacity of that material. If the material exhibits a high swelling value it means that the material can absorb a high amount of chemical or liquid without completely dissolving in the medium. Figure 8 shows that percentage swelling of AHL containing NR/LDPE/wPE composites decrease with the increase of AHL loading from 0 pphp to 1.5 pphp. Composite prepared with AHL loading of $1.5 \mathrm{pphp}$ showed the lowest swelling value compared to other counterparts. Further, the composite prepared without AHL shows the highest swelling value as it does not make better adhesion with NR, LDPE, wPE and $\mathrm{CaCO}_{3}$. This in turn reduces the amount of long branches resulting in a higher value for the percentage of swelling in the organic solvent toluene. According to Figure 8, composite prepared with AHL loading of $1.5 \mathrm{pphp}$ is the best in terms of tensile strength, elongation at break and percentage swelling. Hence, excess AHL present in composite would not restrict swelling.

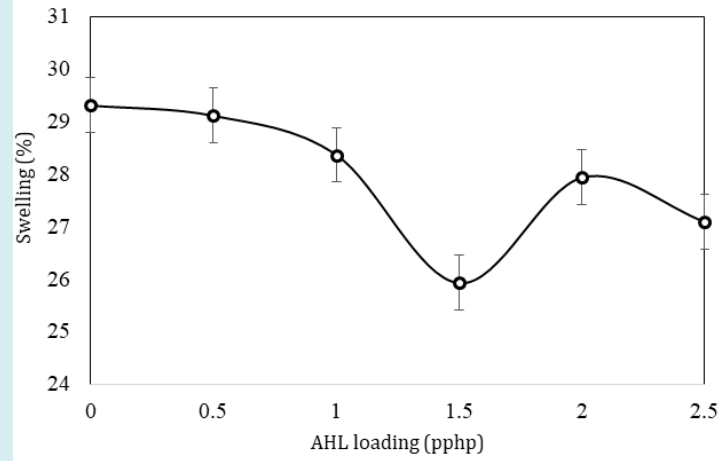

Figure 8: Percentage swelling of NR/LDPE/wPE composites in toluene.

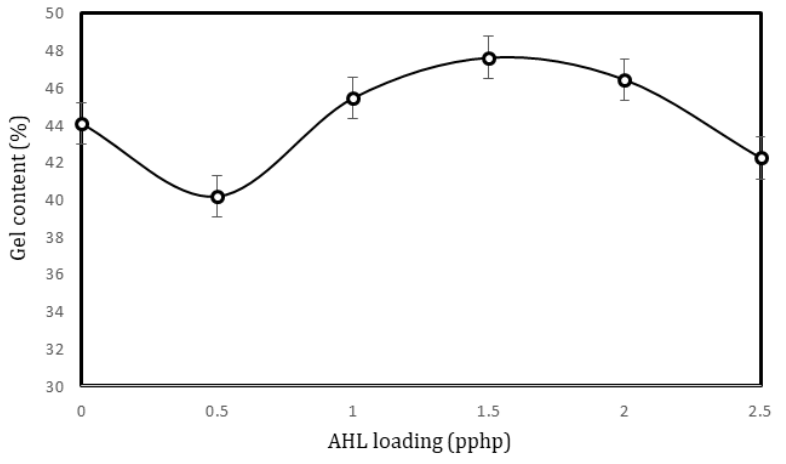

Figure 9: Gel content of NR/LDPE/wPE composites.

Gel content is also used for determining the solvent resistance of a thermoplastic/plastic or rubber material. It 
Physical Science \& Biophysics Journal

is known to be directly proportional to the crosslink density. Higher gel content indicates a higher crosslink density and this results in a lower value for percentage swelling. Percentage gel content gradually increases from AHL loading of $0.5 \mathrm{pphp}$ to $1.5 \mathrm{pphp}$. The composite prepared with 1.5 pphp of AHL has recorded the highest gel content and it is markedly higher than that without AHL. Percentage swelling results (Figure 8) are in agreement with gel content results (Figure 9).

\section{Conclusions}

Incorporation of $1.5 \mathrm{pphp}$ AHL into NR /LDPE/wPE composites improve most of the properties in term of tensile strength, elongation at break, swelling properties and gel content. Water absorption also increased with the increase of AHL loading up to $2 \mathrm{pphp}$ and then decreased. Further, composite prepared with AHL loading at 1.5 pphp showed the lowest solvent absorption, hence it reflected better solvent resistance compared to other counterparts. Results in overall indicate that the composite with $1.5 \mathrm{pphp}$ loading of AHL is the best in terms of properties.

\section{References}

1. Prasad KMR, Virupaksha TK (1990) Purification and characterization of a protease from jackfruit latex. Phytochemistry 29(6): 1763-1766.

2. Mekkriengkrai D, Ute K, Swiezewska E, Chojnacki T, Tanaka Y, et al. (2004) Structural characterization of rubber from jackfruit and euphorbia as a model of natural rubber. Biomacromolecules 5(5): 2013-1019.

3. Fonseca KC, Morais NC, Queiroz MR, Silva MC, Gomes MS, et al. (2010) Purification and biochemical characterization of Eumiliin from Euphorbia milii var. hislopii latex. Phytochemistry 71(7): 708-715.

4. Orwa C, Mutua A, Kindt R, Jamnadass R, Simons A (2009) Agroforestree Database:a tree reference and selection guide version 4.0 .

5. Mariano OP (2014) Compatibilizers.

6. Mariano M, El Kissi N, Dufresne A (2014) Cellulose nanocrystals and related nanocomposites: review of some properties and challenges. Journal of Polymer Science Part B: Polymer Physics 52(12): 791-806.

7. Sethuraj MR, Mathew NT (2012) Natural rubber: biology, cultivation and technology. $1^{\text {st }}($ Edn.), Volume 23, Elsevier Science.

8. Major IR absorption bands and possible assignment in the typical FTIR spectrum of saffron.

9. Rector YP (2006) Polymers Characteristics, Applications and Processing. $2^{\text {nd }}(E d n$.$) , University of Virginia, USA.$

10. Bhadra S, Mohan N, Parikh G, Nair S (2019) Possibility of artocarpus heterophyllus latex as an alternative source for natural rubber. Polymer Testing 79.

11. Sampath WDM, Egodage SM, Edirisinghe DG (2019) Effect of an organotitanate coupling agent on properties of calcium carbonate filled low-density polyethylene and natural rubber composites. Journal of the National Science Foundation of Sri Lanka 47(1): 17-27.

12. Brook GS (2013) Polyethylene.

13. Pocius AV (2012) Adhesion and Adhesives Technology: An Introduction. Carl Hanser Verlag GmbH Co KG, pp: 370.

14. Clark RJ (1995) Raman microscopy: application to the identification of pigments on medieval manuscripts. Chemical Society Reviews 24(3): 187-196.

15. Gohain HC, Sahu BP (2017) Formulation and evaluation of mucoadhesive tablet of metformin hcl using jack fruit latex (Artocarpus heterophyllus). International Journal of Drug Research and Technology 6(3): 182-192. 